Support Information for the Manuscript Entitled

\title{
Synthesis and Characterization of Triptych $\mu$-ABC Star Triblock Copolymers
}

\author{
Zhibo Li ${ }^{\dagger}$, Marc A. Hillmyer*, ${ }^{,}$, and Timothy P. Lodge* ${ }^{, \dagger,}$ \\ Departments of Chemistry and Chemical Engineering and Materials Science, \\ University of Minnesota, \\ Minneapolis, Minnesota 55455
}

\section{Table of Contents}

1. MALDI-TOF spectrum a PBD homopolymer precursor. S2

2. 2D-COSY ${ }^{1} \mathrm{H}$ NMR spectrum of PBD homopolymer precursor $\quad$ S4

3. ${ }^{1} \mathrm{H}$ NMR spectrum of PEE homopolymer precursor. S5

4. Elemental analysis results of $\mu$-EOF star triblock copolymers $\quad$ S6

\footnotetext{
*Authors for correspondence: hillmyer@chem.umn.edu, lodge@chem.umn.edu

'Department of Chemistry

${ }^{\star}$ Department of Chemical Engineering and Materials Science
} 
Hetero-bifunctional PBD Structure Analysis by MALDI-TOF MS. Figure S1 (a) shows the MALDI-TOF spectrum of a MMO end functionalized PBD homopolymer precursor, where the interval between two adjacent major peaks corresponds to the molecular weight of a butadiene unit. The molecular weight distributions over repeat unit was then mapped after subtracting the mass of $\mathrm{Ag}^{+}$ion, and a straight line resulted with a slope of $54\left(\mathrm{C}_{4} \mathrm{H}_{6}\right)$ (Figure $\left.\mathrm{S} 1(\mathrm{~b})\right)$. The experimental molecular weights from MALDI analysis essentially matched to the calculated molecular weights to indicate the desired structure for PBD precursor. The two sets of satellite peaks in the MALDI-TOF spectrum correspond to the termination reactions between polybutadienyllithium and chloromethylmethyl ether, or di-chloromethyl ether, respectively. The byproducts were unable to initiate the polymerization of ethylene oxide and can be removed in the purification process of PEE-PEO diblock copolymer precursors. 

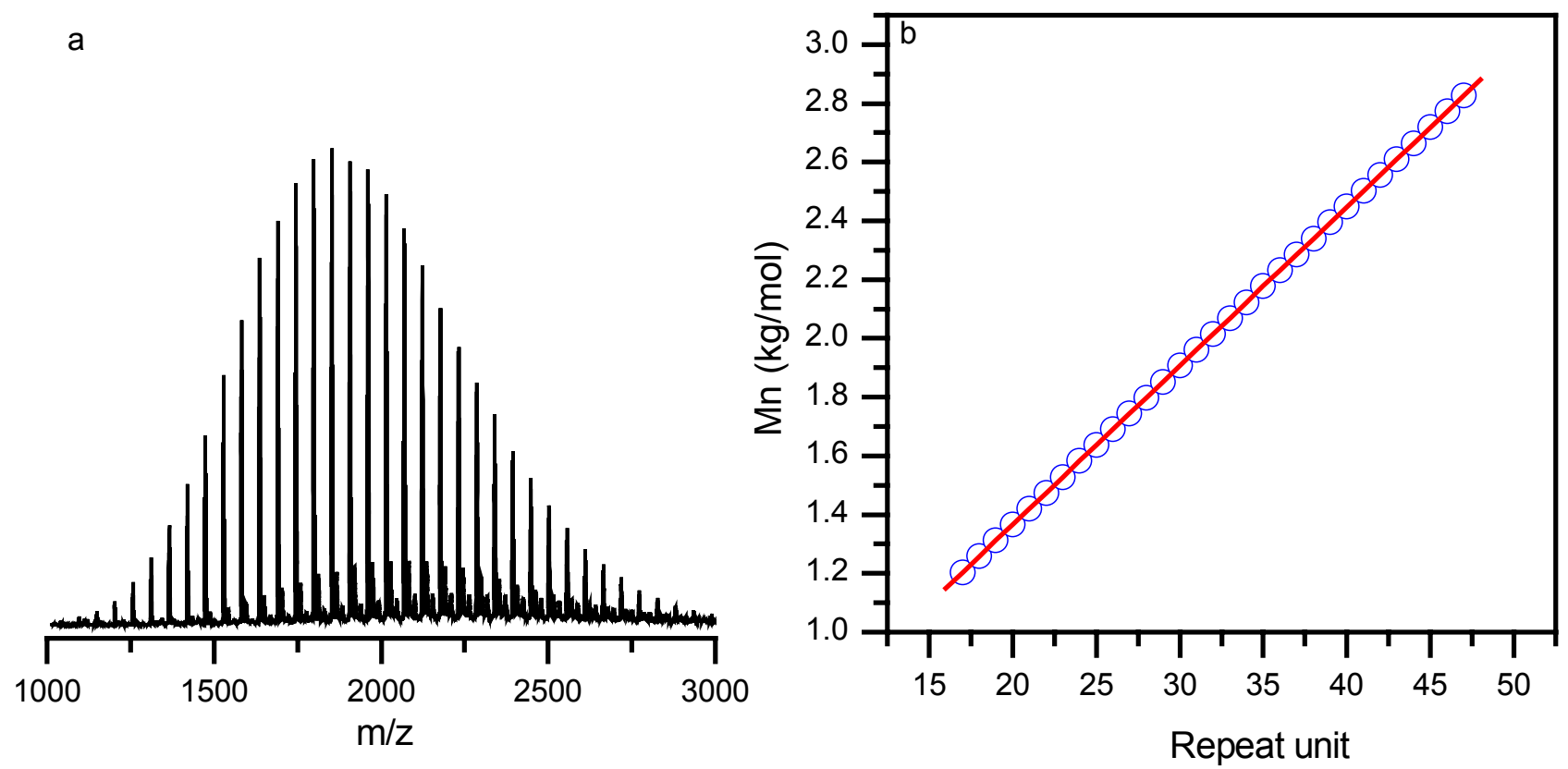

Figure S1 (a): MALDI spectrum of a hetero-bifunctional (PBD)(OH) $\left(\mathrm{CH}_{2} \mathrm{OCH}_{2} \mathrm{OCH}_{3}\right)$ precursor without subtracting the mass mass of $\mathrm{Ag}^{+}$; (b): Molecular weight after subtracting the mass of $\mathrm{Ag}^{+}$versus the repeating unit. The strait line is the calculated $\mathrm{M}_{\mathrm{n}}$ from molecular structure. 


\section{D-COSY ${ }^{1}$ H NMR spectrum of PBD homopolymer precusor. The 2D-COSY}

${ }^{1} \mathrm{H}$ NMR spectrum of PBD homopolymer precursor further corroborates the desired molecular structure as the assignment of NMR resonances in Figure1. For example, in Figure $\mathrm{S} 2$, the $\mathrm{H}-\mathrm{H}$ coupling between adjacent protons such as $\mathrm{H}^{\mathrm{d}}$ and $\mathrm{H}^{\mathrm{c}}, \mathrm{H}^{\mathrm{d}}$ and $\mathrm{H}^{\mathrm{e}}$ were unambiguously determined. These results are consistent with nucleophilic attack on the least substituted carbon of MMO.

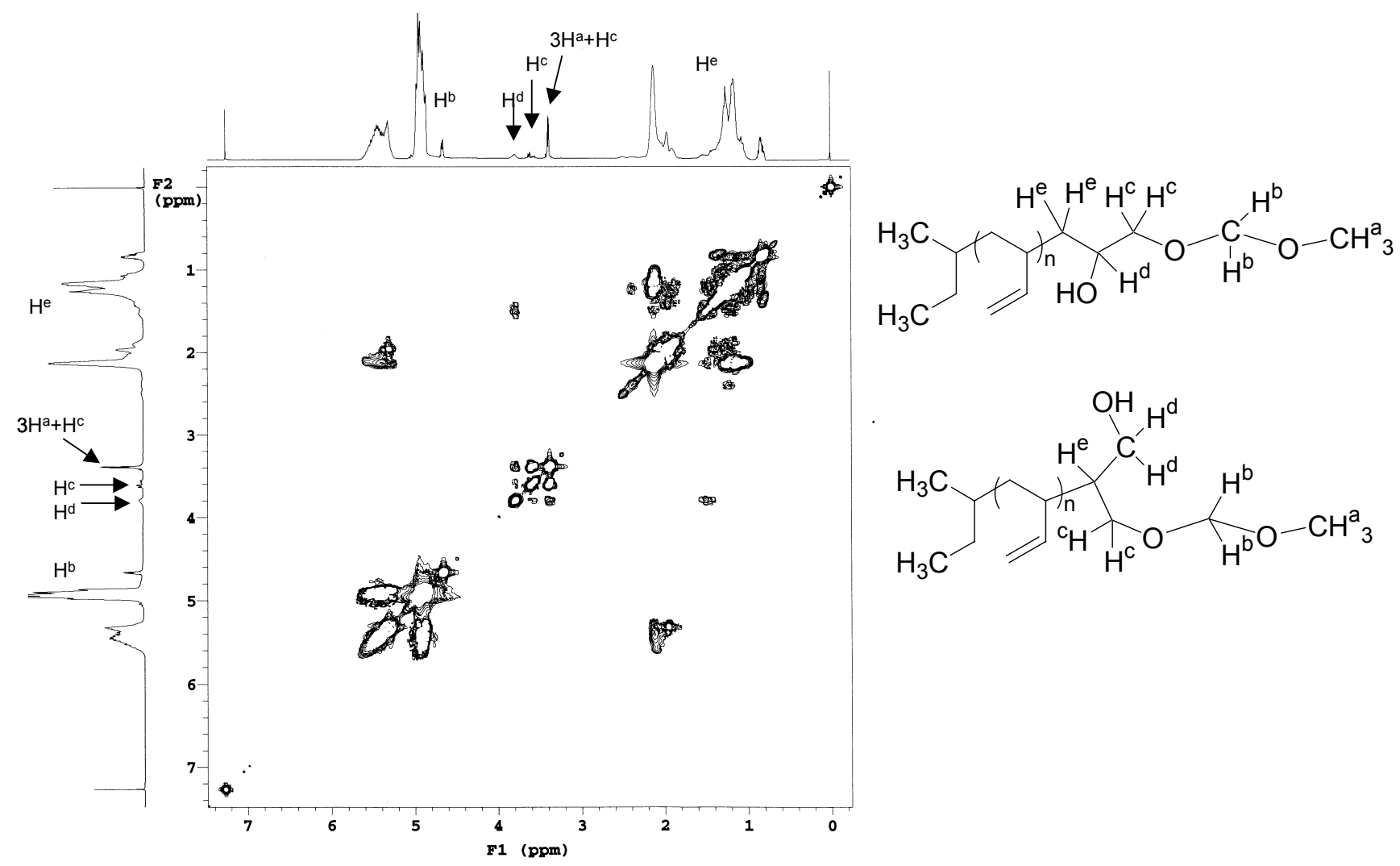

Figure S2. 2D-COSY ${ }^{1} \mathrm{H}$ NMR of $(\mathrm{PBD})(\mathrm{OH})\left(\mathrm{CH}_{2} \mathrm{OCH}_{2} \mathrm{OCH}_{3}\right)$ homopolymer precursor. 
${ }^{1}$ H NMR spectroscopy of PEE precursor. The ${ }^{1} \mathrm{H}$ NMR spectra of PEE suggested a quantitative hydrogenation of the PBD precursor while preserving the end $\mathrm{MMO}$ functional group. The molar ratio between MMO end group and PEE block (based on PBD molecular weight) was used to estimate the average functionality, which showed good consistents with PBD homopolymer precursor.

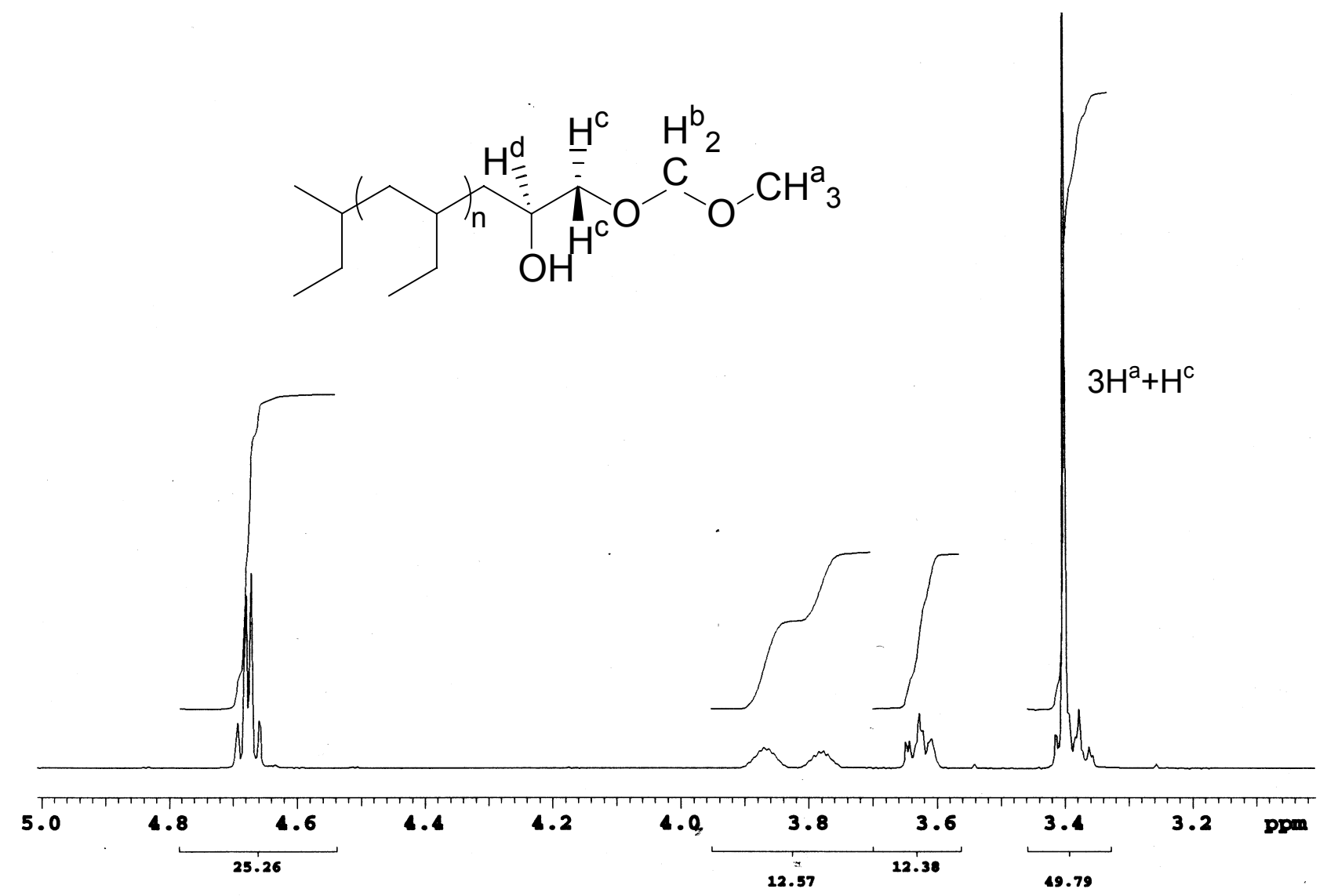

Figure S3 ${ }^{1} \mathrm{H}$ NMR spectrum of a hetero-bifunctional $(\mathrm{PEE})(\mathrm{OH})\left(\mathrm{CH}_{2} \mathrm{OCH}_{2} \mathrm{OCH}_{3}\right)$ homopolymer precursor. 
Elemental Analysis of $\mu$-EOF star triblock copolymer. As we know the molecular weight of each block from ${ }^{1} \mathrm{H}$ NMR spectra, theoretical elemental percentages can be calculated. The experimentally found element percentages for $\mathrm{C}, \mathrm{H}, \mathrm{O}$, and $\mathrm{F}$ are compared with theoretical predictions in Table S1. The detected element percentage matched very well with the theoretical prediction for each element. These results were also taken as strong evidence to confirm the well-defined composition of the obtained $\mu$ EOF star triblock copolymers.

Table S1. Elemental analysis results of $\mu$-EOF star triblock copolymers

\begin{tabular}{|c|c|c|c|c|c|c|c|c|}
\hline \multirow[t]{2}{*}{ Sample } & \multicolumn{4}{|c|}{ Theoretical } & \multicolumn{4}{|c|}{ Experimental } \\
\hline & $\mathrm{C} \%$ & $\mathrm{H} \%$ & $\mathrm{O} \%$ & $\mathrm{~F} \%$ & $\mathrm{C} \%$ & $\mathrm{H} \%$ & $\mathrm{O} \%$ & $\mathrm{~F} \%$ \\
\hline$\mu-\operatorname{EOF}(2-6-2)$ & 52.2 & 7.9 & 22.8 & 17.1 & 51.3 & 7.7 & 23.1 & 17.6 \\
\hline$\mu-\operatorname{EOF}(2-7-2)$ & 52.4 & 8.0 & 23.9 & 15.7 & 51.5 & 7.7 & 23.5 & 17.7 \\
\hline$\mu-\operatorname{EOF}(2-9-2)$ & 52.8 & 8.2 & 26.0 & 13.1 & 51.4 & 7.8 & 25.0 & 15.7 \\
\hline$\mu-\operatorname{EOF}(2-9-3)$ & 50.8 & 7.6 & 24.9 & 16.7 & 49.8 & 7.4 & 24.7 & 18.4 \\
\hline$\mu-\mathrm{EOF}(2-9-5)$ & 47.3 & 6.7 & 23.1 & 22.9 & 44.7 & 5.9 & 22.1 & 27.8 \\
\hline$\mu-\operatorname{EOF}(2-13-2)$ & 53.2 & 8.4 & 28.3 & 10.1 & 52.9 & 8.3 & 28.5 & 10.4 \\
\hline$\mu-\operatorname{EOF}(2-13-3)$ & 51.6 & 8.0 & 27.4 & 13.1 & 52.7 & 8.2 & 27.9 & 11.5 \\
\hline
\end{tabular}

